\title{
Erratum to: Determinants of Survivorship Care Plan Use in US Cancer Programs
}

\author{
Sarah A. Birken • Allison M. Deal • Deborah K. Mayer • \\ Bryan J. Weiner
}

Published online: 6 May 2014

(C) Springer Science+Business Media New York 2014

Erratum to: J Canc Educ

DOI 10.1007/s13187-014-0645-7

Table 1 in the original publication of "Determinants of survivorship care plan use inUnited States cancer programs" (Birken SA, Deal AM, Mayer DK, Weiner BJ; 2014;doi:10.1007/s13187014-0645-7) erroneously excluded an item designation for one

group of response options. The following response options should correspond to the item "In your opinion, what are barriers to SCP use in your cancer program? Please check all that apply.": "There are not enough resources (e.g., time, staff, training, money) to use SCPs"; "Perception that SCPs are difficult to use"; "Influential people (e.g., physician champions, managers) have not advocated for SCPs to be used"; and "Other."

The online version of the original article can be found at http://dx.doi.org/ 10.1007/s13187-014-0645-7.

\footnotetext{
S. A. Birken $(\bowtie) \cdot$ A. M. Deal

Lineberger Comprehensive Cancer Center, The University of North

Carolina at Chapel Hill, Chapel Hill, NC 27599-7411, USA

e-mail: sarah1@email.unc.edu

D. K. Mayer

School of Nursing, The University of North Carolina at Chapel Hill, Carrington Hall \#7460, Chapel Hill, NC 27599-7460, USA
}

\section{B. J. Weiner}

Department of Health Policy and Management, Gillings School of Global Public Health, The University of North Carolina at Chapel Hill, 135 Dauer Drive, Campus Box 7411, Chapel Hill, NC 27599-7411, USA 
Table 1 Survey item response options and frequencies $(n=81)$

Number Item Response options

Frequency

$(\%)$

$1 \quad$ Which of the following options best describes SCP use in your cancer program? Please check one.

SCPs are used regularly. $\rightarrow$ Please proceed to Question 3. $\quad 15.00$

SCPs are used sometimes. $\rightarrow$ Please proceed to Question 3. $\quad 30.00$

SCPs were previously used, but we no longer use them. $\rightarrow$ Please 0.00 proceed to Question 3.

SCPs are not used, but we are planning to use them. $\rightarrow$ Please $\quad 51.25$ SKIP to Question 8.

SCPs are not used, and we do not plan to use them. $\rightarrow$ Please $\quad 3.75$ SKIP to Question 9.

2 Approximately when did SCP use begin in your cancer 1995

program? Please enter an approximate start date or check 2006-2009

"Don't Know."

2010-2013

83.32

Approximately what percentage of providers in your cancer program has used SCPs? Please check one percentage or "Don't Know."

$0-25 \%$

26-50\%

51-75\%

For approximately what percentage of all survivors in your cancer center are SCPs developed? Please check one percentage or check "Don't Know."

Don't know

0-25\%

76-100\%

Don't know

76-100\%

For survivors in which tumor groups have SCPs been/will SCPs be used? Please check all that apply.

Breast

Other

\section{LIVESTRONG Care Plan}

American Society for Clinical Oncology (ASCO) Survivorship

Other

Desire to comply with American College of Surgeons (ACoS)

Desire to comply with National Comprehensive Cancer Network 53.95 (NCCN) guidelines

Desire to comply with American Society for Clinical Oncology (ASCO) practice guidelines 
Table 1 (continued)

11 Approximately how many new cancer patients are seen in

12 Please enter the ZIP code where your cancer program is

Urban $\quad 88.60$ located. ${ }^{\mathrm{c}}$

Rural

13 Please indicate your cancer program type. Please check all that apply. ${ }^{\mathrm{a}}$

Community hospital comprehensive cancer program

Community hospital cancer program

Teaching hospital cancer program

Other

14 Of which professional society/societies is your cancer program a member? Please check all that apply.

American College of Surgeons (ACoS) Commission on Cancer

Association of Community Cancer Centers (ACCC)

American Society for Clinical Oncology (ASCO) Quality

Other

${ }^{\mathrm{a}}$ The percent of responses to infrequently selected options have been collapsed. Specific response options and frequencies are available upon request from SB

${ }^{\mathrm{b}}$ Average number of new cancer patients per year

${ }^{\mathrm{c}}$ ZIP codes identified as urban or rural using Rural-Urban Commuting Areas data 